\title{
A Review of Milling of Gamma Titanium Aluminides
}

\author{
S. Castellanos ${ }^{1}$, J. Lino Alves ${ }^{2}$ \\ ${ }^{1}$ Department of Mechanical Engineering, Faculty of Engineering, University of Porto, Rua Dr. \\ Roberto Frias, 4200-465 Porto, Portugal. University of Armed the Forced ESPE, Sangolqui, \\ Ecuador (up201406881@fe.up.pt); 2Department of Mechanical Engineering, Faculty of \\ Engineering, University of Porto, Rua Dr. Roberto Frias, 4200-465 Porto, Portugal \\ (falves@fe.up.pt) ORCID 0000-0002-9327-9092
}

\begin{abstract}
Intermetallic titanium aluminide alloys are used in the high technology engineering field with the goal of achieving weight reduction in different components, exposed to corrosive environments and high temperatures in aeronautical and automotive industries. Despite their attractive properties such as low density, high strength, high stiffness and good corrosion, creep and oxidation resistance, the machinability of titanium aluminide alloys is difficult due to its high hardness, chemical reactivity, and low ductility. This article reviews the state of the art regarding the machinability of titanium aluminide alloys and focuses on the analysis of the milling process, namely the process parameters, surface integrity and cutting tools. The influence of titanium aluminides properties on the machinability is also discussed presenting some current trends and further needed research.
\end{abstract}

Author Keywords. Industrial Research, Mechanization, Technological Process, Milling, Gamma Titanium Aluminides, Surface Quality

Type: Research Article

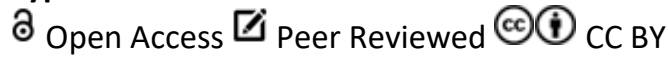

\section{Introduction}

Currently, in the aerospace and automotive industries, Gamma titanium aluminide alloys are presented as a better alternative in parts which are exposed to work temperatures around $800^{\circ} \mathrm{C}$ (Appel and Wagner 2001). These alloys are considered an interesting option to replace the nickel-based superalloys because of their enhanced physical and mechanical properties such as lower density, strength and stiffness, corrosion resistance, creep and oxidation resistance (Table 1). In the past, these attractive properties of Gamma TiAl were not fully exploited due to the difficulty in processing and machining these alloys at room temperature.

\begin{tabular}{lcc}
\hline \multicolumn{1}{c}{ Property } & Gamma-TiAl alloys & Nickel based Superalloys \\
\hline Density $\left(\mathrm{g} / \mathrm{cm}^{3}\right.$ ) & $3.7-3.9$ & 8.3 \\
Young Modulus RT (GPa) & $160-176$ & 206 \\
Yield Strength (MPa) & $400-630$ & 1000 \\
Tensile Strength (MPa) & $450-700$ & 1200 \\
Ductility at room Temperature (\%) & $1-3$ & 15 \\
Creep limit $\left({ }^{\circ} \mathrm{C}\right)$ & 1000 & 1090 \\
Oxidation $\left({ }^{\circ} \mathrm{C}\right)$ & $900-1000$ & 1090 \\
Hardness (HV10) & $285-350$ & $320-390$ \\
\hline
\end{tabular}

Table 1: Summary of properties of Gamma TiAl and Nickel based superalloys (Kothari, Radhakrishnan, and Wereley 2012) 
On the other hand, room temperature ductility, fracture toughness and fatigue crack growth are also complex characteristics on the processing of the titanium aluminides. Nonetheless, advances in manufacturing technologies, a better understanding of microstructure and deformation mechanisms, has led to their commercial use. This material has a particular interest in the production of rotating parts in gas turbine aero-engine for aeronautical industry and is also used to conrod, engine valves and turbine wheels of turbochargers for automotive engine applications. These applications, report that the reduction in weight compared to conventional nickel-based super alloys implies fuel saving, an increase in engine efficiency and consequently a reduction of $\mathrm{CO}_{2}$ emission (Appel, Paul, and Oehring 2011).

The brittle nature, high chemical reactivity, high strength and relatively low heat conductivity strongly contribute to extra difficulties in the machining process of titanium aluminides. Nevertheless, these inconveniences pose challenges to the machining field technology players, such as cutting tool manufacturers and materials researchers.

Another challenge is that the manufacture of parts for aeronautical and automotive industries requires, generally, high dimensional accuracy and good surface integrity, being the machining process an essential procedure for reaching these requirements on accuracy and productivity (Zitoune, Krishnaraj, and Davim 2013).

Nowadays, in the titanium aluminides machining field, a lack of specific technical information such as cutting parameters, tool geometries, tools materials, coatings, cutting fluids, among others, slow down their commercial use and research. Most of the research in titanium aluminides machining is conducted using the existent information for titanium Ti-6Al-4V allow, which has been the most extensively studied alloy of the group of titanium alloys.

According to several researchers (Aust and Niemann 1999; Aspinwall, Dewes, and Mantle 2005; Beranoagirre, Olvera, and López de Lacalle 2012; Ge, Fu, and Xu 2007; Mantle and Aspinwall 2001; Weinert, Bergmann, and Kempmann 2006), low thermal conductivity, low elastic modulus, high strength and the brittle nature of titanium aluminides are the main factors for their poor machinability. These factors conduct to the rapid degradation of the machining tools, low material removal rate, and low surface quality of machined parts.

Some researchers have been dedicated to the development of titanium aluminides machinability, where optimization of the integrity surface(Mantle and Aspinwall 2001; Kolahdouz et al. 2015; Bentley, Mantle, and Aspinwall 1999; Priarone et al. 2016; Priarone, Rizzuti, Rotella, et al. 2012; Radkowski and Sep 2014), selection of cutting parameters (Aspinwall, Dewes, and Mantle 2005; Aust and Niemann 1999; Beranoagirre, Olvera, and López de Lacalle 2012; Bruhis, Sebring, and Noland 2008; Priarone, Rizzuti, Settineri, et al. 2012; Weinert, Bergmann, and Kempmann 2006), tool wear (Vargas Pérez 2005; Priarone et al. 2016; Priarone, Rizzuti, Rotella, et al. 2012; Barakchi Fard and Feng 2009; Priarone, Rizzuti, Settineri, et al. 2012), machining environment (Priarone et al. 2011; Aspinwall et al. 2013; Barakchi Fard and Feng 2009), are the main topics focus of research.

The machining process involves many variables as can be seen in Figure 1 (ASM International 1989), and so a comprehensive review would be complex. This article is focused on the milling process, with especial attention to the cutting parameters, surface roughness, cutting environment and the influences of the material properties on machinability are also highlighted. 


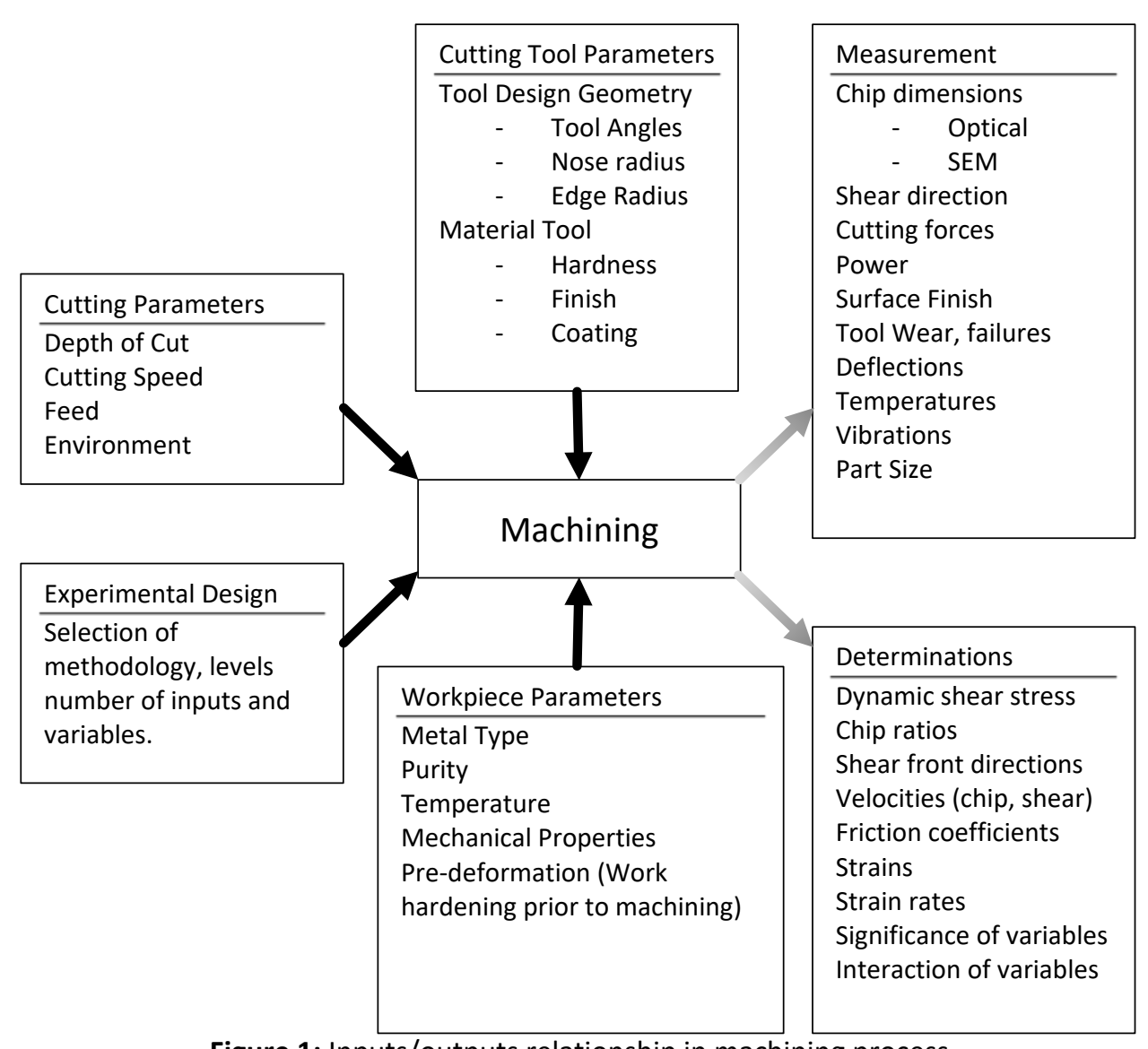

Figure 1: Inputs/outputs relationship in machining process (adaptated of ASM International 1989)

\section{Gamma TiAl properties and Machining}

Gamma Titanium Aluminides present low machinability due to their low thermal conductivity, high reactivity, low ductility, high hardness and strength and work hardening feature.

The thermal conductivity of Ti-based intermetallic alloys (about $22 \mathrm{~W} / \mathrm{mK}$ ) as Gamma TiAl typically contain $45 \% \mathrm{Al}$, is three times higher tthan in titanium alloys (about $7.3 \mathrm{~W} / \mathrm{mK}$ ) and markedly lower than aluminum alloys (about $170-200 \mathrm{~W} / \mathrm{mK}$ at $0^{\circ} \mathrm{C}$ ) (Appel, Paul, and Oehring 2011), but the induced wear or their adverse impact on workpiece integrity by thermal effects in titanium aluminides are not less significant than in classical titanium alloys such as Ti-6Al4V.

Considering the properties shown in Table 1, especially tensile strength, yield strength and hardness, one can understand that the Gamma-TiAl alloys require less machining power than the Ni-based superalloys (Aspinwall et al. 2013), but due to their low ductility (typically quoted between 1-3\%), generally titanium aluminide show poor workpiece integrity.

Conventional machining of Gamma-TiAl is significantly more difficult than with standard titanium alloys, in terms of tool wear, tool life, cutting forces, temperature, productivity and workpiece surface integrity. Furthermore, a lack of correct machining parameters, specific tool geometries and other operation technological aspects, affect the parts surface integrity that tend to exhibit microcrack formation, deformed surface drag and increased surface micro hardness (see Table 2). 


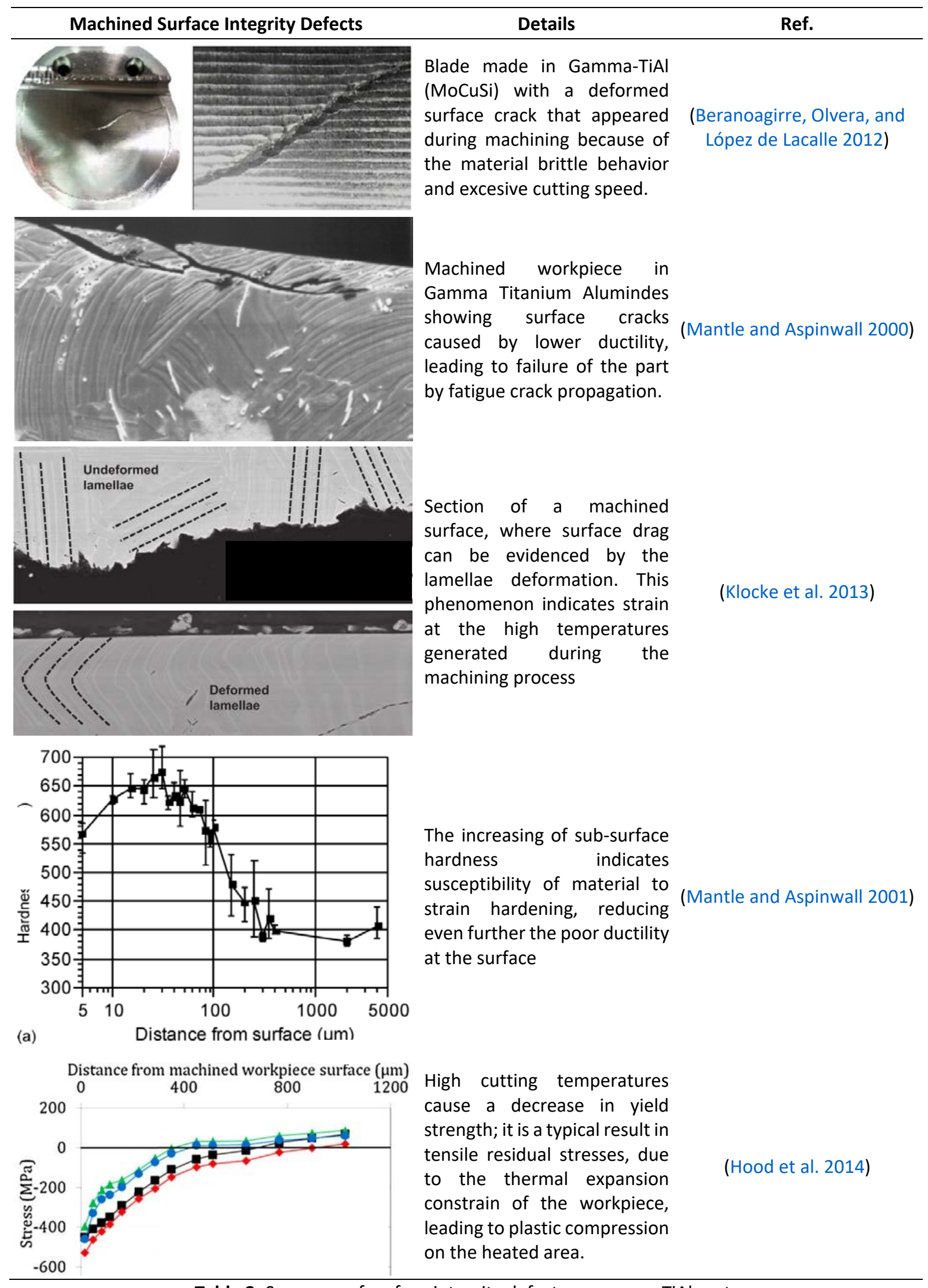

Table 2: Summary of surface integrity defects on gamma TiAl parts 


\section{Milling of Gamma TiAl}

Research reports on Milling of titanium aluminides are focused on the analysis and improvement of the machined surface integrity. These studies involve several considerations such us: surface finish, absence of cracks, evidence of thermal damage and adverse residual stress. Surface finish is by far the most important for machining operations, being the main requirement in the more common applications of Gamma TiAl alloys (automotive and aeronautical fields). The surface integrity researches are conducted assessing a combination of different values of cutting parameters. Machining tests are carried out with cutting speed values from $20 \mathrm{~m} / \mathrm{min}$ (Aust and Niemann 1999) to $600 \mathrm{~m} / \mathrm{min}$ (Kolahdouz et al. 2015), feed rates from $0.005 \mathrm{~m} / \mathrm{min}$ (Kolahdouz et al. 2015) to $0.12 \mathrm{~m} / \mathrm{min}$ (Aspinwall et al. 2013) and depth of cut from $0.1 \mathrm{~mm}$ (Kolahdouz et al. 2015) to $5 \mathrm{~mm}$ (Aust and Niemann 1999). Table 3 provides some cutting parameters studied on optimization of surface roughness for machining improvement.

On the other hand, cutting tools designed for machining of titanium alloys (commonly small diameter radius end and ball end milling cutters) have been tested. Furthermore machining research (Aspinwall et al. 2013; Barakchi Fard and Feng 2009; Vargas Pérez 2005; Priarone et al. 2016) shows that only cemented carbide C/W or harder cutting materials like CBN (cubic boron nitride) and PCD (Polycrystalline Diamond) can be used because of the high hardness and brittleness as well as the high strength of this material. The data, obtained from Taguchi methodology, normally cover assessment of tool materials, coatings, operating modes and parameters, fluid application, tool wear and workpiece surface roughness and integrity.

In the studies developed for the milling of titanium aluminates, interesting information is presented, where it is observed that the values of surface roughness obtained are between 0.8-0.155 $\mu \mathrm{m}$. These results are achieved using common tools with TiAIN coatings to machine titanium based alloys (alpha, beta and alpha + beta) under different cutting environments.

On the other hand, the limited information that is available about the machining of titanium aluminides opens a new and interesting research area where it is still necessary to determine the influences of the tool properties such as materials, coatings and geometries, and their influence on the characteristics of the workpiece (surface integrity and roughness). Furthermore, as in other materials, it is also important to define the optimum cutting parameters in the production of parts for the machining of gamma TiAl alloys. 


\begin{tabular}{|c|c|c|c|c|c|c|c|c|}
\hline \multirow{2}{*}{ Ref. } & \multicolumn{2}{|l|}{ Material } & Tool & \multicolumn{4}{|c|}{ Machining Parameters } & \multirow{2}{*}{$\begin{array}{l}\text { Surface } \\
\text { Roughness } \\
\text { ( } \mu \mathrm{m})\end{array}$} \\
\hline & Specification & Type & Material & $\begin{array}{l}\text { Cutting } \\
\text { Speed } \\
\mathrm{m} / \mathrm{min}\end{array}$ & $\begin{array}{c}\text { Feed } \\
\text { (mm/tooth) }\end{array}$ & $\begin{array}{l}\text { Axial } \\
\text { Depth } \\
(\mathrm{mm})\end{array}$ & Environment & \\
\hline (Aust and Niemann 1999) & TiAl primary Casting & End Mill & Carbide K10-K20 & $\begin{array}{l}17 \\
20\end{array}$ & $\begin{array}{l}0.01 \\
0.04\end{array}$ & $1-5$ & $\begin{array}{l}\text { wet (Emulsion } 1: 15 \text { ) } \\
\text { to } 1.31 \mathrm{t} / \mathrm{min}\end{array}$ & $\begin{array}{c}2.95 \\
0.8\end{array}$ \\
\hline (Ge, Fu, and Xu 2007) & Ti-48Al-2Cr-2Nb & End Mill & $\begin{array}{l}\text { Solid Carbide } \\
\text { (TiAIN) }\end{array}$ & $\begin{array}{l}120 \\
240\end{array}$ & 0.08 & 5 & Dry & $\begin{array}{l}0.198 \\
0.176\end{array}$ \\
\hline $\begin{array}{l}\text { (Beranoagirre, Olvera, and } \\
\text { López de Lacalle 2012) }\end{array}$ & $\begin{array}{c}\text { Ti-45Al- }(5-10) \mathrm{Nb}-(0,2-0,4) \mathrm{C} \\
\text { and Ti- }(43-46) \mathrm{Al}-(1-2) \mathrm{Mo}- \\
(0,2) \mathrm{Si}-\mathrm{Cu}\end{array}$ & End Mill & $\begin{array}{l}\text { Solid Carbide } \\
\text { (TiAIN) }\end{array}$ & $\begin{array}{l}60 \\
70\end{array}$ & 0.06 & 1 & $\begin{array}{l}\text { Wet (Emulsion FU } 70 \\
\text { W Rhenus pH 7.7-8.8) } \\
61 \mathrm{t} / \mathrm{min}\end{array}$ & $\begin{array}{l}0.51 \\
0.31\end{array}$ \\
\hline (Hood et al. 2013) & $\begin{array}{c}\text { and Ti-45Al-2Mn-2Nb+0.8\% } \\
\text { Vol TiB2XD }\end{array}$ & $\begin{array}{l}\text { Ball nose } \\
\text { end mill }\end{array}$ & $\begin{array}{l}\text { Solid Carbide } \\
\text { (TiAIN PVD) }\end{array}$ & $\begin{array}{l}160 \\
250\end{array}$ & 0.06 & 0.25 & Dry & $\begin{array}{l}0.6 \\
0.3\end{array}$ \\
\hline (Settineri et al. 2014) & $\begin{array}{l}\text { Ti-48Al-2Cr-2Nb, Ti-45Al- } \\
2 \mathrm{Mn}-2 \mathrm{Nb}+0.8 \% \text { Vol TiB2XD, } \\
\text { Ti-43,5Al-4Nb-1Mo-0.1B }\end{array}$ & $\begin{array}{l}\text { Toroidal } \\
\text { end mill }\end{array}$ & $\begin{array}{l}\text { Solid Carbide } \\
\text { (TiAIN PVD) }\end{array}$ & 90 & 0.1 & 0.3 & $6 \%$ Emulsion to 6 bar & $\begin{array}{l}1.7 \\
0.5\end{array}$ \\
\hline (Kolahdouz et al. 2015) & Ti-48Al-2Cr-2Nb-1B (\%at) & End Mill & $\begin{array}{l}\text { Solid Carbide } \\
\text { (TiAIN-PVD } \\
\text { microcoating) }\end{array}$ & $\begin{array}{l}600 \\
300\end{array}$ & 0.005 & 0.1 & $\begin{array}{l}\text { Dry and MQL } 50 \mathrm{ml} / \mathrm{h} \\
\text { at } 50 \mathrm{~mm} \text { from the } \\
\text { tool tip }\end{array}$ & $\begin{array}{l}0.170 \\
0.155\end{array}$ \\
\hline
\end{tabular}




\section{Conclusions}

The properties of titanium aluminides such as high strength at elevated temperature produced during machining, high elastic modulus and chemical reactivity, thermal conductivity and low ductility have an adverse effect on the machinability of these intermetallic alloys. The published research agrees that the latter two are the most degrading factors.

Most of the research focuses on the adverse influence of low ductility and strength at high temperature, that leads to a lower surface integrity, sub-surface micro hardening, higher instability of the machining process and the fast wear of tool cutting edge.

Research on machining gamma-TiAl alloys started two decades ago, and has been contributing to an increase understanding of the microstructure, deformation and the relationships between these features and the cutting parameters on machining. Although the available information, currently there is still a lack of knowledge about the right (optimal) machining parameters for this materials, and besides there are also few studies on quantification of chemical reactivity between titanium aluminide and tool material, or the relationship between workpiece hardening and cutting parameters, tool geometry or cutting fluids.

Most of the investigation carried out on the machinability of gamma TiAl alloys is based on different cutting conditions, which makes it difficult to be compared, and be implemented in practical cases of producing optimized parts.

\section{References}

Appel, Fritz, Jonathan D. H. Paul and Michael Oehring. 2011. Gamma titanium aluminide alloys: Science and technology. Weinheim: Wiley-VCH.

Appel, F. and R. Wagner. 2001. "Intermetallics: Titanium aluminides". In Encyclopedia of Materials: Science and Technology, 4246-4264. Oxford: Elsevier. DOI: 10.1016/B0-08043152-6/00745-2.

ASM International. 1989. Metals Handbook, Vol. 16: Machining (ASM Handbook). Edited by T. E. Aaron, Gary Adam, John Agapiou, M. S. Ahmed, G. Albares, and Tom Andrew. $9^{\text {th }}$ ed. Metals Park, Ohio: ASM International.

Aspinwall, David. K., R. C. Dewes and Andrew L. Mantle. 2005. "The machining of $\gamma$-TiAl intermetallic alloys". CIRP Annals - Manufacturing Technology 54 (1):99-104. DOI: 10.1016/S0007-8506(07)60059-6.

Aspinwall, David K., Andrew L. Mantle, Wai Kok Chan, Richard Hood and Sein Leung Soo. 2013. "Cutting temperatures when ball nose end milling $\mathrm{Y}$-TiAl intermetallic alloys". CIRP Annals - Manufacturing Technology 62 (1):75-78. DOI: 10.1016/j.cirp.2013.03.007.

Aust, Eckhard, and Hans-Reinhard Niemann. 1999. "Machining of $\mathrm{\gamma}$-TiAl". Advanced Engineering Materials 1 (1):53-57.

Barakchi Fard, M. Javad and Hsi-Yung Feng. 2009. "Effect of tool tilt angle on machining strip width in five-axis flat-end milling of free-form surfaces". The International Journal of Advanced Manufacturing Technology 44 (3):211-222. DOI: 10.1007/s00170-008-1828-3.

Bentley, S. A., Andrew. L. Mantle and David. K. Aspinwall. 1999. "The effect of machining on the fatigue strength of a gamma titanium aluminide intermetallic alloy". Intermetallics 7 (8):967-969. DOI: 10.1016/S0966-9795(99)00008-4.

Beranoagirre, A., D. Olvera and L. N. López de Lacalle. 2012. "Milling of gamma titaniumaluminum alloys". The International Journal of Advanced Manufacturing Technology 62 (1):83-88. DOI: 10.1007/s00170-011-3812-6. 
Bruhis, Yair, William Sebring and Dennis Noland. 2008. High performance milling. Niagara Cutter.

Ge, Ying Fei, Yu Can Fu, and Jiu Hua Xu. 2007. "Experimental study on high speed milling of $Y^{-}$ TiAl alloy". Key Engineering Materials 339:6-10. DOI: 10.4028/www.scientific.net/KEM.339.6.

Hood, Richard, David K. Aspinwall, C. Sage and W. Voice. 2013. "High speed ball nose end milling of -TiAl alloys". Intermetallics 32:284-291. DOI: 10.1016/j.intermet.2012.09.011.

Hood, Richard, David K. Aspinwall, Sein Leung Soo, Andrew L. Mantle and Donka Novovic. 2014. "Workpiece surface integrity when slot milling $\mathrm{Y}$-TiAl intermetallic alloy". CIRP Annals - Manufacturing Technology 63 (1):53-56. DOI: 10.1016/j.cirp.2014.03.071.

Klocke, Fritz, Luca Settineri, Dieter Lung, Paolo Claudio Priarone and Martin Arft. 2013. "High performance cutting of gamma titanium aluminides: Influence of lubricoolant strategy on tool wear and surface integrity". Wear 302 (1-2):1136-1144. DOI: 10.1016/j.wear.2012.12.035.

Kolahdouz, S., M. Hadi, B. Arezoo and S. Zamani. 2015. "Investigation of surface integrity in high speed milling of gamma titanium aluminide under dry and minimum quantity lubricant conditions". Procedia CIRP 26:367-372. DOI: 10.1016/j.procir.2014.08.016.

Kothari, Kunal, Ramachandran Radhakrishnan and Norman M. Wereley. 2012. "Advances in gamma titanium aluminides and their manufacturing techniques". Progress in Aerospace Sciences 55:1-16. DOI: 10.1016/j.paerosci.2012.04.001.

Mantle, Andrew L., and David K. Aspinwall. 2000. "Cutting force evaluation when high speed end milling a gamma titanium aluminide intermetallic alloy". In Intermetallics and Superalloys, edited by D. G. Morris, S. Naka Moris and P. Caron, 209-215. Wiley-VCH Verlag $\mathrm{GmbH} \&$ Co. KGaA.

- - . 2001. "Surface integrity of a high speed milled gamma titanium aluminide". Journal of Materials Processing Technology 118 (1-3):143-150. DOI: 10.1016/S0924-0136(01)00914-1.

Priarone, Paolo Claudio, Fritz Klocke, Maria Giulia Faga, Dieter Lung and Luca Settineri. 2016. "Tool life and surface integrity when turning titanium aluminides with PCD tools under conventional wet cutting and cryogenic cooling". The International Journal of Advanced Manufacturing Technology 85 (1):807-816. DOI: 10.1007/s00170-015-7958-5.

Priarone, Paolo Claudio, Stefania Rizzuti, Giovanna Rotella and Luca Settineri. 2011. "Technological and environmental aspects in milling of $\mathrm{\gamma}$-TiAl". Advanced Materials Research 223:340-349. DOI: 10.4028/www.scientific.net/AMR.223.340.

- - - 2012. "Tool wear and surface quality in milling of a gamma-TiAl intermetallic". The International Journal of Advanced Manufacturing Technology 61 (1):25-33. DOI: 10.1007/s00170-011-3691-X.

Priarone, Paolo Claudio, Stefania Rizzuti, Luca Settineri and Guido Vergnano. 2012. "Effects of cutting angle, edge preparation, and nano-structured coating on milling performance of a gamma titanium aluminide". Journal of Materials Processing Technology 212 (12):26192628. DOI: 10.1016/j.jmatprotec.2012.07.021.

Radkowski, Grzegorz and Jaroslaw Sep. 2014. "Surface quality of amilled gamma titaniumaluminide for aeronautical applications". Management and Production Engineering Review 5 (2):60. DOI: 10.2478/mper-2014-0018.

Settineri, Luca, Paolo Claudio Priarone, Martin Arft, Dieter Lung and Todor Stoyanov. 2014. "An evaluative approach to correlate machinability, microstructures, and material 
properties of gamma titanium aluminides". CIRP Annals - Manufacturing Technology. 63 (1):57-60. DOI: 10.1016/j.cirp.2014.03.068.

Vargas Pérez, R. G. 2005. "Wear mechanisms of WC inserts in face milling of gamma titanium aluminides". Wear 259 (7-12):1160-1167. DOI: 10.1016/j.wear.2005.02.062.

Weinert, Klaus, Stefan Bergmann and Christoph Kempmann. 2006. "Machining sequence to manufacture a $\gamma$-TiAl-conrod for application in combustion engines". Advanced Engineering Materials 8 (1-2):41-47. DOI: 10.1002/adem.200500200.

Zitoune, R., V. Krishnaraj and J. Paulo Davim, eds. 2013. Machining of titanium alloys and composites for aerospace applications. Trans Tech Publications. 